\title{
Performance analysis of Diesel engines fueled by biodiesel blends via thermodynamic simulation of an air-standard Diesel cycle
}

\author{
H. Shahmirzae Jeshvaghani • M. Fallahipanah • \\ M. Hashemi Gahruei $\cdot$ L. Chen
}

Received: 19 June 2012/Revised: 30 December 2012/ Accepted: 16 March 2013/Published online: 17 April 2013

(C) Islamic Azad University (IAU) 2013

\begin{abstract}
Because of environmental problems, it becomes necessary to develop alternative fuels that give engine performance at par with diesel. Among the alternative fuels, biodiesel and its blends hold good promises as an eco-friendly and the most promising alternative fuel for Diesel engine. The properties of biodiesel and its blends are found similar to that of diesel. Many researchers have experimentally evaluated the performance characteristics of conventional Diesel engines fueled by biodiesel and its blends. However, experiments require enormous effort, money and time. Hence, via finite-time thermodynamics simulation, an air-standard Diesel cycle model with heat transfer loss and variable specific heats of working fluid is analyzed to predict the performance of Diesel engine. The effect of compression ratio, cut-off ratio and fuel type on output work and thermal efficiency is investigated through the model. The fuels considered for the analysis are conventional diesel, rapeseed oil biodiesel and its blend (20\% biodiesel and $80 \%$ diesel by volume). Numerical simulations showed that the output work and thermal efficiency of the engine decrease with increase of cut-off ratio for all fuels. Also, the model predicts similar performance with diesel and biodiesel blend which means that
\end{abstract}

H. Shahmirzae Jeshvaghani $(\bowtie) \cdot$ M. Fallahipanah

Department of Agricultural Engineering, Faculty of Agriculture, University of Shahrekord, Shahrekord, Iran

e-mail:shahmirzae@gmail.com

M. Hashemi Gahruei

Department of Mechanical Engineering, Faculty of Engineering,

University of Shahrekord, Shahrekord, Iran

L. Chen

Postgraduate School, Naval University of Engineering,

Wuhan, People's Republic of China the biodiesel blend (20\% biodiesel and $80 \%$ diesel by volume) could be a good alternative and eco-friendly fuel for conventional Diesel engines without any need to modify the engine.

Keywords Finite-time thermodynamics - Irreversible Diesel cycle · Numerical simulation - Output work · Rapeseed oil - Thermal efficiency

\section{Introduction}

One of the most important elements to affect the world economy and politics is substantially of petroleum resources which are the main sources of world energy supply. In today's world, in order to meet the growing energy needs as a consequence of spiraling demand and diminishing supply and also because of environmental issues concerned with the exhaust gases emission by the usage of fossil fuels, alternative energy sources mostly biofuels are receiving more attention (Oner and Altun 2009; Aksoy 2011).

Biodiesel is an alternative diesel fuel consisting of fatty acid alkyl monoesters derived from vegetable oil, waste animal fats or waste cooking oil. These oils are identified as one of the future contenders to fulfill the demand gap produced by the depletion of fossil diesel fuels (Ma and Hanna 1999; Zheng et al. 2007) and to reduce environmental problems. Biodiesel is known as a carbon neutral fuel because the carbon present in the exhaust was originally fixed from the atmosphere. In comparison with conventional diesel fuels, the fuel-borne oxygen in biodiesel may promote more complete combustion and thus reduce particulate matter (PM), carbon monoxide (CO) and total hydrocarbons (THC) in compression-ignition engines, 
while slightly increase nitrogen oxides $\left(\mathrm{NO}_{\mathrm{x}}\right)$ (Zheng et al. 2008). According to a review on emission data for heavyduty engines published by EPA (Environmental Protection Agency of USA 2002), from diesel to B20 (20\% biodiesel and $80 \%$ diesel by volume), $\mathrm{CO}, \mathrm{HC}$ and PM decreased by 13, 20 and $20 \%$ respectively (Lapuerta et al. 2008). Because of its reproducibility, nontoxicity and sulfur-free properties, a considerable amount of recent researches have focused on experimental performance analysis of Diesel engine fueled by various sources of biodiesel and its blends (Dasilva et al. 2003; Raheman and Phadatare 2004; Ramadhas et al. 2005; Usta 2005; Labeckas and Slavinskas 2006; Reyes and Sepulveda 2006; Rao et al. 2007; Rehman et al. 2007; Tsolakis et al. 2007; Hu et al. 2008). Furthermore, due to its similar physical properties to diesel fuel, there is no need to modify the engine when it is fueled by biodiesel blends (Graboski and McCormick 1998; Ramadhas et al. 2004; Srivathsan et al. 2008; Atadashi et al. 2010; Liu et al. 2011; Zhang et al. 2011).

Although biodiesel can be used in modern unmodified compression-ignition Diesel engines in neat form, it is more commonly encountered as a blend component in petrodiesel, such as B20 (Moser et al. 2009). Currently, blends of B6 to B20 are allowed by ASTM D7467 (2008). Dhar et al. (2012) demonstrated that combustion duration for biodiesel blends was shorter than mineral diesel. This indicates that lower blends of biodiesel (up to B20) can be used in unmodified CI engines without any compromise in engine performance and emission characteristics. Agarwal and Das (2001) indicated that B20 gives better engine performance and less emission. Shehata and Abdel Razek (2011) found that B20 is promising as an alternative fuel for Diesel engine. The utilization of vegetable oils does not require a significant modification of existing engines. This can be seen as the main advantage of vegetable oils. Today, B20 is recommended to be used since it is a good mediator among cost, emission, cold weather and material match and solubility problems (Oguz et al. 2010).

As stated above, researchers have experimentally analyzed the performance characteristics of Diesel engines fueled by biodiesel and its blends. However, experiments require enormous effort, money and time. A thermodynamic simulation model could reduce such effort. Diesel engine combustion models are mainly described as thermodynamic and fluid dynamic models. Many significant achievements have been made since finite-time thermodynamics was introduced to analyze and optimize the performance of real heat-engines (Bejan 1996; Chen and Sun 2004.

Numerical simulation based on finite-time thermodynamic modeling of Diesel engine processes has long been used as an aid by design engineers to develop new design concepts. Mozurkewich and Berry (1982) and Hoffman et al. (1985) used mathematical techniques, developed in optimal-control theory, to reveal the optimal motions of the pistons in Diesel and Otto cycle engines, respectively. Chen et al. (1998) evaluated internal-combustion engine cycles using the optimal motion of a piston fitted in a cylinder containing a gas pumped at a specified heatingrate. Orlov and Berry (1993) deduced the power and efficiency limits for internal-combustion engines. AnguloBrown et al. (1994); Chen et al. (2002) and Wang et al. (2002) modelled Otto, Diesel and Dual cycles with friction losses during a finite time. Klein (1991) investigated the effects of heat transfer on the performance of Otto and Diesel cycles. Chen et al. (1996) and Lin et al. (1999) derived the relations between the net power and efficiency for Diesel, Otto and Dual cycles via consideration of the heat-transfer losses. Chen et al. (2003, 2004) determined the characteristics of power and efficiency for Otto, Dual cycles with heat transfers and friction losses. Al-Sarkhi et al. (2006) determined the performance of an irreversible Diesel cycle with losses arising from heat resistance and friction. Al-Hinti et al. (2008) evaluated the maximum net power output and cycle thermal efficiency of an air-standard Diesel cycle as functions of more realistic parameters such as cut-off ratio.

However, with biodiesel as a new source of Diesel engine fuel, very few works have been done by researchers and it is still a newer area of research. Gogoi and Baruah (2010) described a cycle simulation model for predicting the performance of a Diesel engine fueled by diesel and also different blends of diesel and biodiesel, under varying speed and compression ratio conditions. They indicated that B20, B40 and B60 presented an increase in thermal efficiency compared to diesel. Al-Dawody and Bhatti (2011) theoretically investigated the performance and emissions of Diesel engine operating on diesel oil and different Soybean Methyl Ester (SME) blends using the simulation software Diesel-RK. Among all tested fuels, they noticed that B20 was the best tested fuel which gave the same performance results with good reduction in emissions as compared to pure diesel operation.

The present study describes an air-standard irreversible Diesel cycle model. This model follows finite-time thermodynamic changes of the working fluid through the engine intake, compression, combustion, expansion and exhaust processes for predicting the performance of a Diesel engine fueled by diesel, biodiesel and B20. Numerical simulations predict the performance of engine in terms of output work and thermal efficiency at different compression and cut-off ratios for all the fuels. Fuel properties and engine design and operating parameters are specified as inputs to the model. This study was carried out in Shahrekord Universities in Iran during the year spring 2012. 


\section{Materials and methods}

General description of the model

\section{Thermodynamic simulation of an air-standard irreversible Diesel cycle}

Figure 1 shows a pressure-volume diagram of thermodynamic process of an air-standard Diesel cycle. Diesel cycle is first introduced by Rudolf Diesel based on his engine which is known as Diesel engine today. As shown in Fig. 1, in an air-standard Diesel cycle, the compression process $1 \rightarrow 2$ is isentropic, which represents the compression stroke in a compression-ignition engine. Heat is added to the cycle during combustion process $2 \rightarrow 3$ which is an isobaric one. Throughout isentropic process $3 \rightarrow 4$ which is representing the power stroke in the heat engine, expansion is occurred. Finally, the heat rejection process $4 \rightarrow 1$ which completes the cycle is a constant volume heat rejection process, an isochoric one. As is usual in finitetime thermodynamic heat-engine cycle models, there are two instantaneous adiabatic-processes, namely $1 \rightarrow 2$ and $3 \rightarrow 4$. For the heat addition and heat rejection $(2 \rightarrow 3$ and $4 \rightarrow 1$ stages, respectively), it is assumed that heating occurs from state 2 to state 3 and cooling ensues from state 4 to state 1 .

In a real cycle, the specific heat of the working fluid varies with temperature and this will have a significant influence on the performance of the cycle. Assuming the specific heat of the working fluid as a function of temperature alone, over the temperature range generally encountered for gases in heat engines (300-2,200 K), the specific heat curve is nearly linear and to a close approximation:

$$
\begin{aligned}
& C_{v}=b+k T \\
& C_{p}=a+k T,
\end{aligned}
$$

where $a, b$ and $k$ are constants and $C_{v}$ and $C_{p}$ are isochoric and isobaric heat capacity of working fluid, respectively.

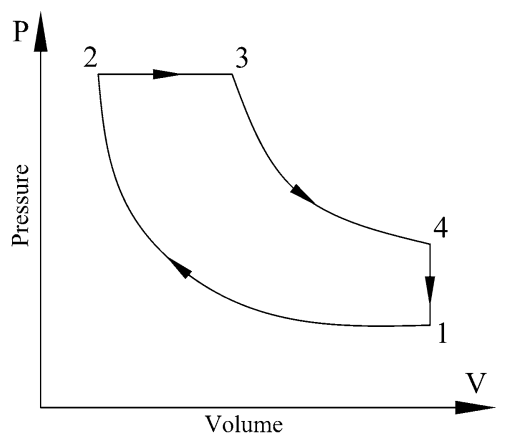

Fig. 1 Pressure-volume diagram of an air-standard Diesel cycle
Accordingly, it is obvious that the universal gas constant, $R$, of the working fluid is:

$R=C_{p}-C_{v}=a-b$

During the process of $2 \rightarrow 3$ which is a constant pressure process, the heat added to the working fluid could be calculated from the following equation:

$Q_{i n}=M \int_{T_{2}}^{T_{3}} C_{p} d T=M \int_{T_{2}}^{T_{3}}(a+k T) d T=M\left[a\left(T_{3}-T_{2}\right)+0.5 k\left(T_{3}^{2}-T_{2}^{2}\right)\right]$

and during process $4 \rightarrow 1$, which is a constant volume process, the heat rejected by the working fluid is:

$Q_{\text {out }}=M \int_{T_{1}}^{T_{4}} C_{v} d T=M \int_{T_{1}}^{T_{4}}(b+k T) d T=M\left[\left(b\left(T_{4}-T_{1}\right)+0.5 k\left(T_{4}^{2}-T_{1}^{2}\right)\right]\right.$,

where $M$ is the mole number of the working fluid.

Because $C_{v}$ and $C_{p}$ are dependent on temperature, the adiabatic exponent $k=C_{p} / C_{v}$ will also vary with temperature. Therefore, the equation often used for a reversible adiabatic-process, with constant $k$, cannot be used for a reversible adiabatic-process with variable $k$. However, a suitable engineering approximation for the reversible adiabatic-process with variable $k$ can be assumed (i.e. the process can be broken up into a large number of infinitesimally small steps and for each of these, the adiabatic exponent $k$ can be regarded as a constant) (Al-Sarkhi et al. 2006; Ghatak and Chakraborty 2007). For example, any reversible adiabatic-process between states $i$ and $j$ can be regarded as consisting of numerous infinitesimally small processes, for each of which a slightly different value of $k$ applies. For any of these processes, when infinitesimally small changes in temperature $d T$ and in volume $d V$ of the working fluid ensue, the equation for the reversible adiabatic-process with variable $k$ can be written as follows:

$T V^{r_{c}-1}=(T+d T)(V+d V)^{r_{c}-1}$

For each small phase (for example $i$ to $j$ ):

$k\left(T_{j}-T_{i}\right)+b \ln \left(\frac{T_{j}}{T_{i}}\right)=-R \ln \left(\frac{V_{j}}{V_{i}}\right)$

So, the isentropic process of $1 \rightarrow 2$ and $3 \rightarrow 4$ can be rewritten based on (7) as follows:

$k\left(T_{2}-T_{1}\right)+b \ln \left(\frac{T_{2}}{T_{1}}\right)=R \ln r_{c}$

$k\left(T_{3}-T_{4}\right)+b \ln \left(\frac{T_{3}}{T_{4}}\right)=R \ln \left(\frac{r_{c}}{\beta}\right)$,

where in these equations $r_{c}$ is compression ratio and $\beta=\frac{V_{3}}{V_{2}}$ is cut-off ratio. In this study, in order to make conditions closer to the reality, the heat losses from heat transfer to 
outside of the cycle were noted. Thus, it is assumed that (i) the heat loss through the cylinder wall is proportional to the difference of the average temperature of the working fluid and that of the cylinder wall and (ii) during the operation, the wall temperature remains approximately constant. The heat added to the working fluid by combustion is given by the following linear-relation (Klein 1991; Orlov and Berry 1993; Chen et al. 1996; Qin et al. 2003; Ge et al. 2005; Ghatak and Chakraborty 2007):

$Q_{i n}=M\left[A-B\left(T_{2}+T_{3}\right)\right]$,

where in this equation, $A$ and $B$ are constant amounts which are related to the heat transferred to walls and combustion. When the values of $\beta, r_{c}$ and $T_{1}$ are given, $T_{2}$ could be calculated from Eq. (8). Then, substituting from Eq. (4) into Eq. (10) yields the following equation which $T_{3}$ can be obtained from:

$A-B\left(T_{2}+T_{3}\right)-a\left(T_{3}-T_{2}\right)-0.5 k\left(T_{3}^{2}-T_{2}^{2}\right)=0$

Also, $T_{3}$ is achieved from Eq. (11) and then, $T_{4}$ can be derived from Eq. (9). Substituting $T_{1}, T_{2}, T_{3}$ and $T_{4}$ into Eqs. (12) and (13) permits the work and efficiency to be estimated. Then, the relations among output work, thermal efficiency, compression ratio and cut-off ratio of the cycle can be derived.

$W=Q_{\text {in }}-Q_{\text {out }}=M\left[a\left(T_{3}-T_{2}\right)-b\left(T_{4}-T_{1}\right)+0.5 k\left(T_{1}^{2}+T_{3}^{2}-T_{2}^{2}-T_{4}^{2}\right)\right]$

$\eta=1-\frac{Q_{\text {out }}}{Q_{\text {in }}}=1-\frac{b\left(T_{4}-T_{1}\right)+0.5 k\left(T_{4}^{2}-T_{1}^{2}\right)}{a\left(T_{3}-T_{2}\right)+0.5 k\left(T_{3}^{2}-T_{2}^{2}\right)}$

\section{Results and discussion}

Design conditions and numerical simulation

Required engine design parameters and constants (Table 1) are derived from previous studies (Ge et al. 2005; AlSarkhi et al. 2006; Ge et al. 2006; Dzida and Prusakiewicz 2008; Lin and Hou 2008).

The physical and chemical Properties of diesel, biodiesel and B20 fuels are given in Table 2. Biodiesel used in this study is mainly fatty acids methyl esters of rapeseed oil, which fulfilled norm EN 14214 (Dzida and Prusakiewicz 2008).

Table 3 shows the relative $\mathrm{a}, \mathrm{b}$ and $\mathrm{k}$ to calculate the specific heat constants of diesel, biodiesel and B20 fuels (Ge et al. 2005; Al-Sarkhi et al. 2006; Ge et al. 2006; Dzida and Prusakiewicz 2008; Lin and Hou 2008).

Using above values for mentioned engine parameters including the mechanical and thermodynamic parameters and loss coefficients, Eqs. (12) and (13) have been numerically solved to obtain the graphical variation of
Table 1 Engine design parameters and constants used in numerical analysis

\begin{tabular}{ll}
\hline$\beta$ & $1.5-3$ \\
$A$ & $60,000 \mathrm{~J} / \mathrm{mole}$ \\
$B$ & $25 \mathrm{~J} / \mathrm{mole} . \mathrm{K}$ \\
$T_{1}$ & $300 \mathrm{~K}$ \\
$M$ & $1.57 \times 10^{-5} \mathrm{kmole}$ \\
\hline
\end{tabular}

cycle's fluid work and thermal efficiency for comparative analyzing of the renewable fuels effects on the performance of a Diesel cycle as discussed below. Though the intent of this study is to demonstrate trends towards simple, easy and costless evaluation of biofuels, an attempt has been made to provide reasonable values for use in these expressions.

Figures 2, 3, 4, 5, 6, 7 show the effects of the temperature-variable specific heats of working fluid on the performance of Diesel cycle with heat irreversible losses. The fluid work and thermal efficiency versus compression ratio characteristics are approximately parabolic-like curves and the fluid work output versus efficiency curve is loop shaped. They reflect the performance characteristics of a real irreversible Diesel cycle engine (Al-Sarkhi et al. 2006). With the change in compression ratio, engine processes that influence its performance and efficiency, namely, combustion rate, heat transfer and friction, also vary. As the compression ratio is increased, the heat loss to the combustion chamber wall and frictional losses decrease (Heywood 1988); hence, there is an improved performance at higher compression ratios. However, there is a limit at which further increase in compression ratio would not be beneficial as it may lead to increasing surface to volume ratio and slower combustion; because at higher compression ratios, the height of the combustion chamber becomes very small. The results predicted by the present model also show an increasing trend with compression ratio for all the fuels (Figs. 2, 3, 4, 5, 6, 7).

The effect of cut-off ratio $(\beta)$ and different fuels on the performance of a Diesel cycle is shown in Fig. 2. This parameter in a real engine represents the amount of piston movement inside cylinder during the time that heat is added to the cycle. Therefore, smaller $\beta$ shows shorter piston movements inside cylinder. Figure 2 demonstrates that by increasing $\beta$, the amount of work done by the fluid at equal compression ratio decreases. So, when designing engines based on Diesel cycle, the shorter time of adding heat to the operating fluid leads to higher output work. In other words, piston must have minimum stroke to obtain more work. It can be seen that diesel and B20 fuels have a close performance in a Diesel cycle engine. 
Table 2 Physical and chemical Properties of diesel, biodiesel and B20 fuels (Dzida and Prusakiewicz 2008)

\begin{tabular}{|c|c|c|c|c|c|}
\hline Property & Units & Diesel & Biodiesel (B100) & $\mathrm{B} 20$ & European standard (EN 14214) \\
\hline Cetane number & - & 54.1 & 51.7 & 51 & $>51$ \\
\hline Cloud point & ${ }^{\circ} \mathrm{C}$ & -14 & - & -10 & - \\
\hline Flash point & ${ }^{\circ} \mathrm{C}$ & 65 & $>130$ & 68 & 120 \\
\hline Kinematic viscosity at $40{ }^{\circ} \mathrm{C}$ & $\mathrm{mm}^{2} / \mathrm{s}$ & 2.7 & 4.5 & 2.88 & $3.5-5.0$ \\
\hline Water content & $\mathrm{mg} / \mathrm{kg}$ & 64 & 88 & 110 & $<500$ \\
\hline Sulfur content & $\mathrm{mg} / \mathrm{kg}$ & 8.8 & 9.7 & 9.9 & $<10$ \\
\hline Carbon residue on $10 \%$ distillation residue & $\% \mathrm{~m} / \mathrm{m}$ & 0.02 & 0.04 & 0.03 & $<0.3$ \\
\hline FAME content & $\% \mathrm{~m} / \mathrm{m}$ & - & 97.5 & 17.7 & $>96.5$ \\
\hline Oxidation stability at $110^{\circ} \mathrm{C}$ & $\mathrm{h}$ & - & 8.1 & - & $>6.0$ \\
\hline Acid value & $\mathrm{mg}$ of $\mathrm{KOH} / \mathrm{g}$ & - & 0.33 & - & $<0.50$ \\
\hline Iodine value & $\mathrm{g}$ of $\mathrm{I}^{2} / 100 \mathrm{~g}$ & - & 115 & - & $<120$ \\
\hline Linoleic acid methyl ester & $\% \mathrm{~m} / \mathrm{m}$ & - & 8.7 & - & $<12$ \\
\hline Methanol content & $\% \mathrm{~m} / \mathrm{m}$ & - & $<0.05$ & - & $<0.20$ \\
\hline Distillation at $101.3 \mathrm{kPa}: 95 \%$ recovered up to & ${ }^{\circ} \mathrm{C}$ & 330 & - & 339 & - \\
\hline Up to $250{ }^{\circ} \mathrm{C}$ recovered & vol. \% & 40 & - & 30 & - \\
\hline Up to $350{ }^{\circ} \mathrm{C}$ recovered & vol. \% & 98 & - & 98 & - \\
\hline
\end{tabular}

Table 3 Relative $a, b$ and $k$ to calculate specific heat constants of diesel, biodiesel and B20 fuels

\begin{tabular}{lllll}
\hline Fuel Type & $k$ & $b$ & $a$ & References \\
\hline Diesel & 0.005372 & 20.1442 & 29.9786 & Al-Sarkhi et al. (2006); Ge et al. (2005, 2006); Lin and Hou (2008) \\
Biodiesel (B100) & 0.008175 & 20.3266 & 28.161 & Dzida and Prusakiewicz (2008) \\
B20 & 0.005932 & 20.1807 & 28.0151 & Dzida and Prusakiewicz (2008) \\
\hline
\end{tabular}

Also, Fig. 2 demonstrates that the cut-off ratio and compression ratio variations influence the fluid work significantly. Gogoi and Baruah (2010) found that for all the fuels the power increased with compression ratio. These variations are similar for all three used fuels, especially diesel and B20 fuels.

Figure 3 shows thermal efficiency variations with compression ratio for different $\beta$ and fuels. According to the plots, it can be seen that for achieving higher thermal efficiencies at a constant compression ratio, one must decrease $\beta$. It should be noted that by decreasing $\beta$, the compression ratio must be increased; but at lower $\beta$ and around maximum thermal efficiency, the curvature of the plot decreases and becomes approximately linear, thus, with small changes in compression ratio around maximum thermal efficiency, no significant change occurs in thermal efficiency and this can be a proper factor in designing engines based on Diesel cycle. Therefore, bigger range of compression ratio changes can be considered in designing which will result in various options for designers.

Also, Fig. 3 demonstrates that biodiesel and B20 fuels have a close performance to diesel fuel in a Diesel cycle and the Diesel engine, when fueled by B20, produces the same amount of thermal efficiency like diesel fuel without need to change engine parameters. Canakci (2007) reported identical thermal efficiency for soybean oil biodiesel (B100), diesel and B20. Dhar et al. (2012) determined the percentage change in performance parameters for B05, B10, B20, B50, B100 blends and diesel fuel with respect to mineral diesel for the entire operating load range of the engine. All blends showed higher thermal efficiency than mineral diesel.

Figure 4 shows fluid work versus thermal efficiency for different $\beta$ and fuels. As is evident from the plot, reduction of $\beta$ increases maximum work done by the operating fluid and the other important issue is that the maximum work can be achieved at higher thermal efficiencies and this is a positive point while designing engines. It is obvious that Diesel engine has the same performance when fueled by each of the fuels which proves the possibility of renewable fuels usage as an alternative for diesel fuel without any modification in engine design. Al-Dawody and Bhatti (2011) point out that biodiesel exhibits similar results with very little performance differences and reductions on regulated emissions when compared to pure diesel baseline operation. Therefore, it may not require modifications on Diesel engines to use biofuels. Aydin and Bayindir (2010) experimentally investigated performance and emissions of 

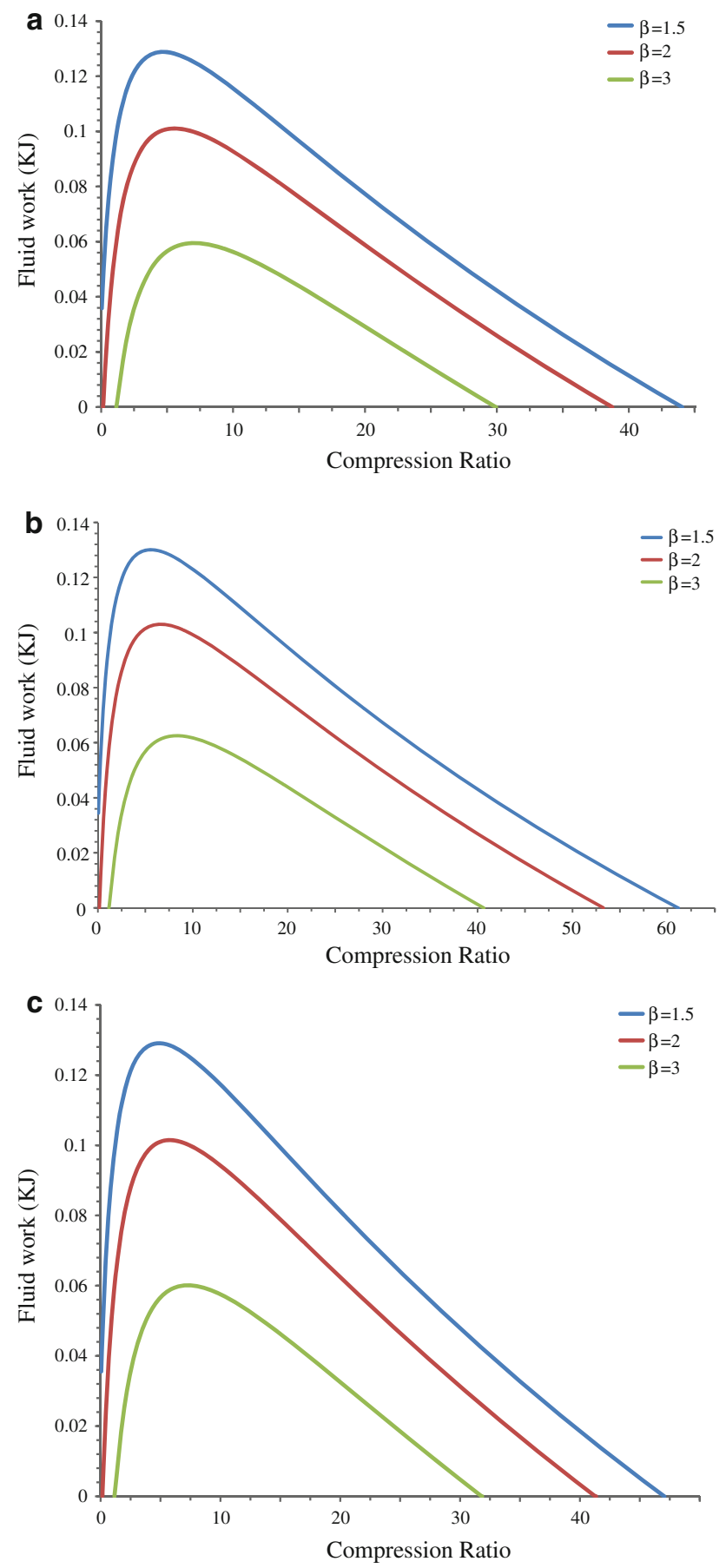

Fig. 2 Fluid work vs. compression ratio for different fuels: a diesel, b biodiesel and c B20

cottonseed biodiesel blends (B5, B20, B50, B75 and B100) in a Diesel engine and stated that there were no significant differences in performance values of B5, B20 and diesel fuel.

Also, Fig. 4 shows that by decreasing the cut-off ratio, an increase of the maximum engine's work will result. Also for a given fluid work, decreasing the cut-off ratio increases
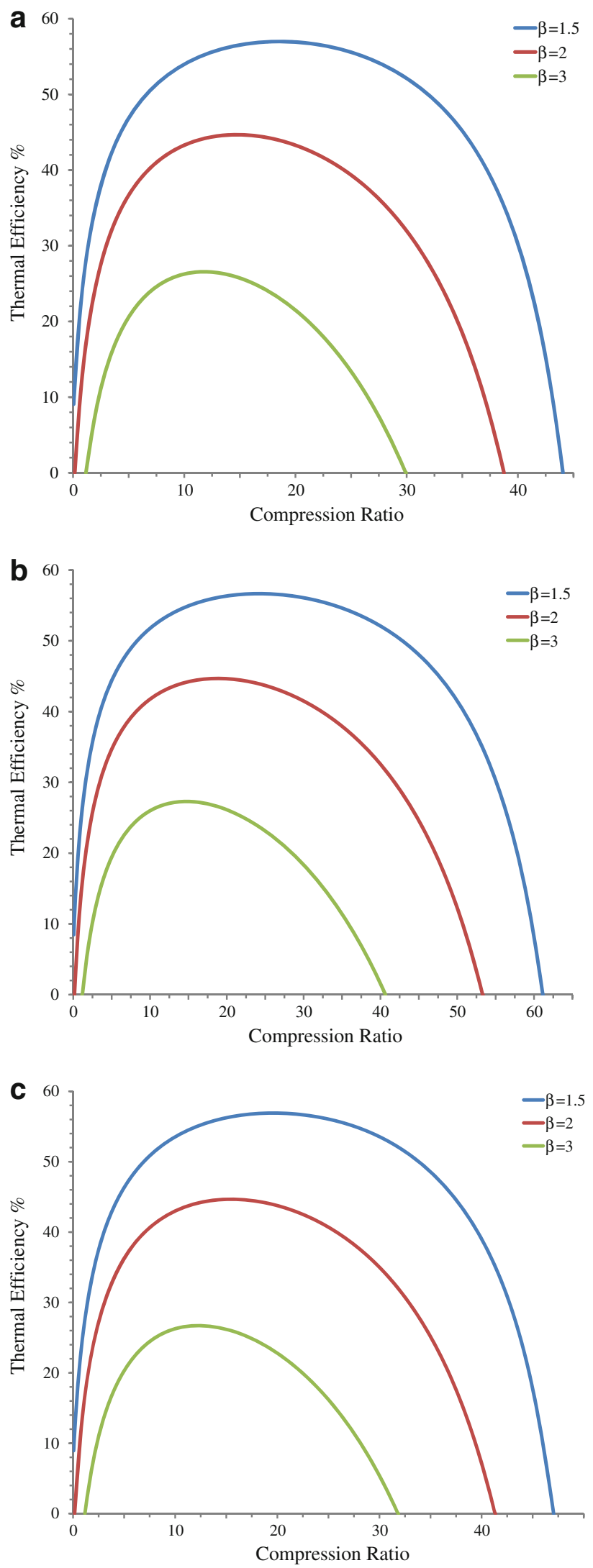

Fig. 3 Thermal efficiency vs. compression ratio for different fuels: a diesel, $\mathbf{b}$ biodiesel and $\mathbf{c}$ B20 

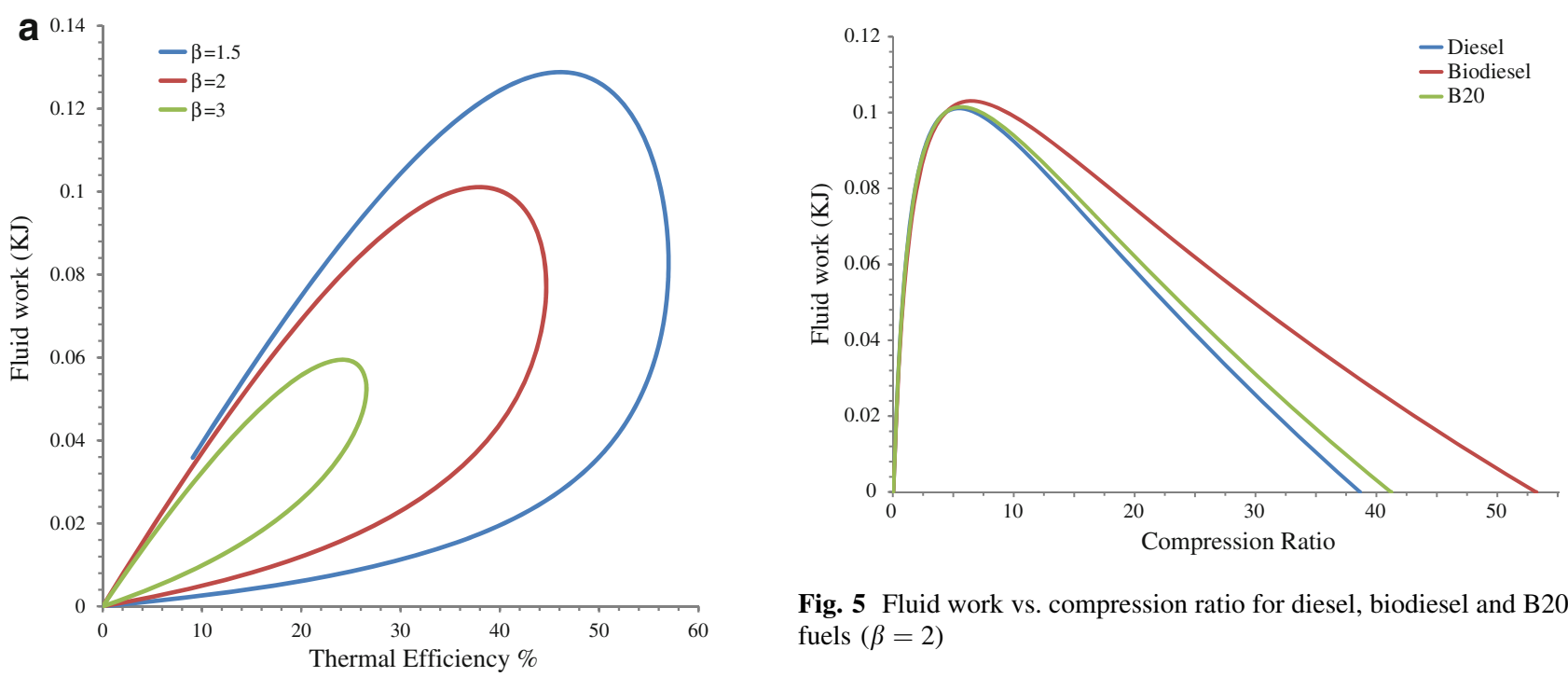

Fig. 5 Fluid work vs. compression ratio for diesel, biodiesel and B20 fuels $(\beta=2)$
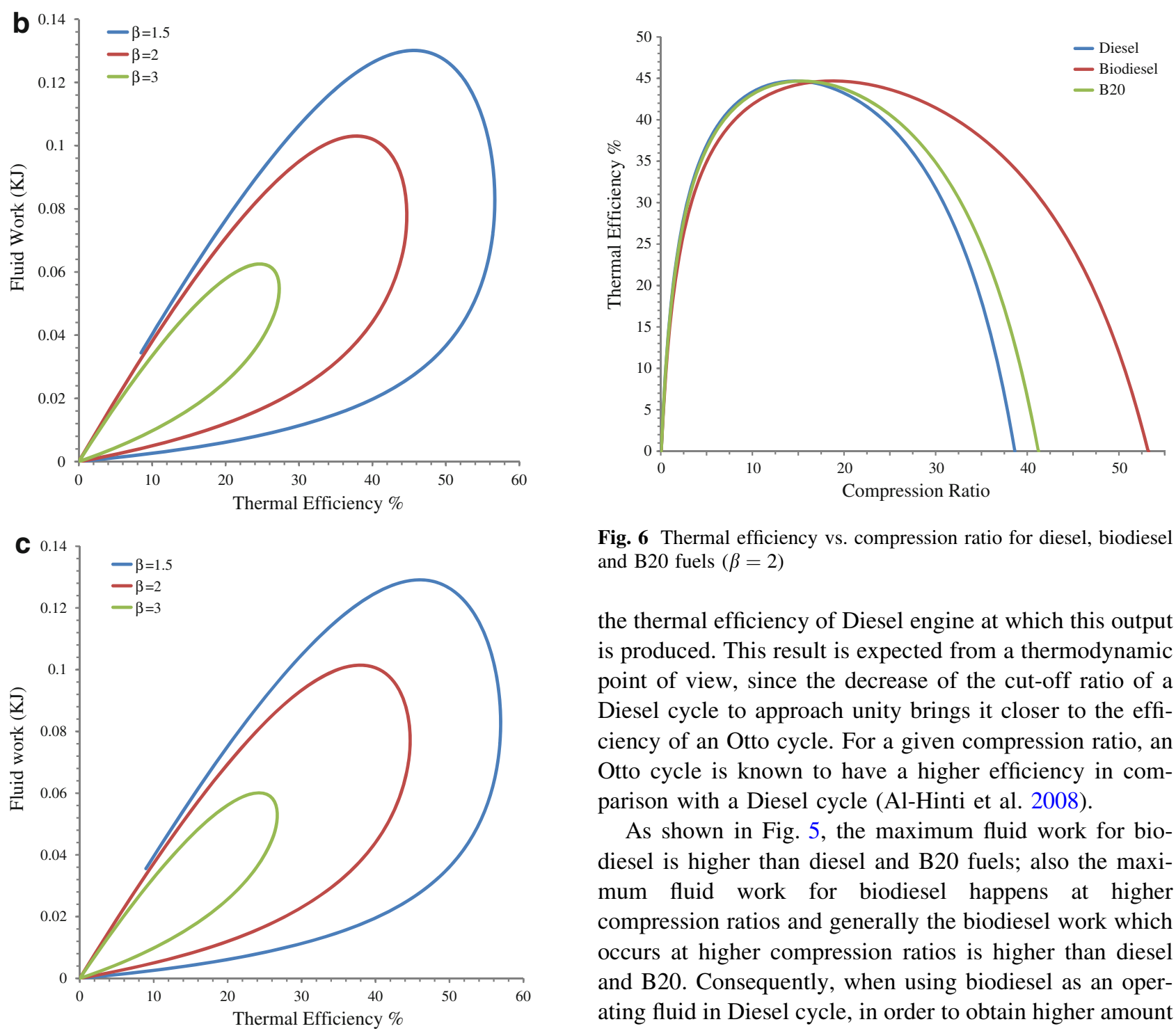

Fig. 4 Fluid work vs. thermal efficiency for different fuels: a diesel, b biodiesel and c B20

Fig. 6 Thermal efficiency vs. compression ratio for diesel, biodiesel and B20 fuels $(\beta=2)$

the thermal efficiency of Diesel engine at which this output is produced. This result is expected from a thermodynamic point of view, since the decrease of the cut-off ratio of a Diesel cycle to approach unity brings it closer to the efficiency of an Otto cycle. For a given compression ratio, an Otto cycle is known to have a higher efficiency in comparison with a Diesel cycle (Al-Hinti et al. 2008).

As shown in Fig. 5, the maximum fluid work for biodiesel is higher than diesel and B20 fuels; also the maximum fluid work for biodiesel happens at higher compression ratios and generally the biodiesel work which occurs at higher compression ratios is higher than diesel and B20. Consequently, when using biodiesel as an operating fluid in Diesel cycle, in order to obtain higher amount of work than diesel fuel, the system must operate under higher compression ratios which means modifying Diesel 


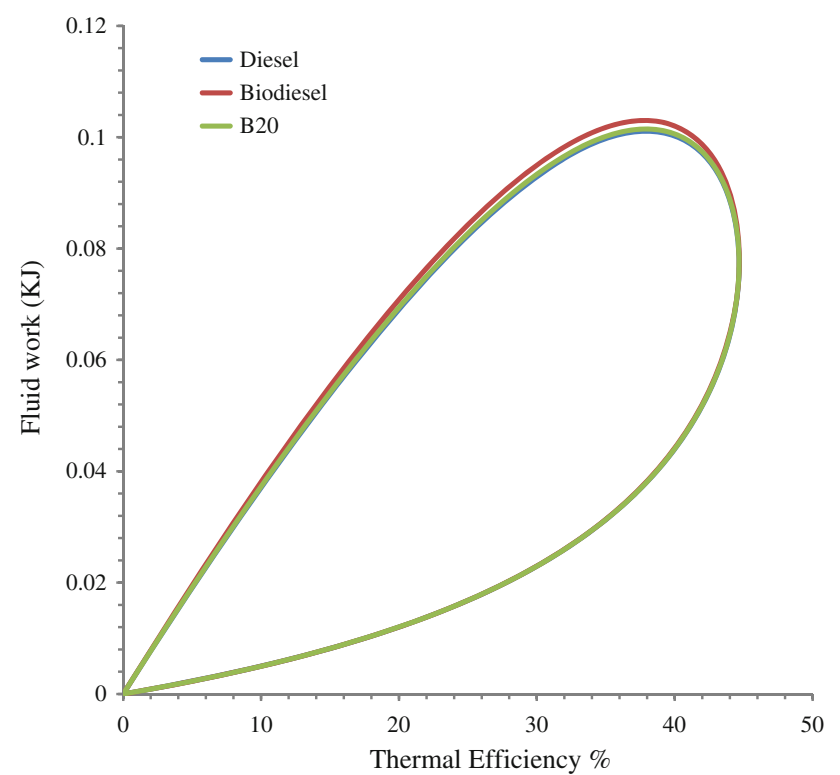

Fig. 7 Fluid work vs. thermal efficiency for diesel, biodiesel and B20 fuels $(\beta=2)$

engine parameters. However, Fig. 5 demonstrates that if the engine is fueled by B20 its output work will approximately be equal to diesel fuel, especially at compression ratios which the fluid work becomes maximum. So, B20 fuel is a good alternative fuel for diesel fuel which can be used in present Diesel engines without any requirement to change engine design. Canakci and Van Gerpen (2003) investigated the effect of biodiesel produced from high free fatty acid feedstock on engine performance and emissions. They stated that energy to work conversion of B20 was equal to that of diesel fuel. Also, as seen in Fig. 4, while using biodiesel fuel to achieve higher engine outputs, higher compression ratios are required. But, diesel and B20 fuels approximately have similar performance in Diesel cycle and could be replaced.

In Fig. 6, it could be found that the maximum thermal efficiency for all three fuels is approximately equal, but this maximum amount of efficiency is achieved at different compression ratios which for diesel, B20 and biodiesel fuels are 12,15 and 17, respectively. This can be a great guide in designing biodiesel engines. Higher thermal efficiency with pure biodiesel was reported by Murrilo et al. (2007). Gogoi and Baruah (2010) found that blends B20, B40 and B60 present an increase in thermal efficiency compared to diesel. Raheman and Phadatare (2004) obtained higher thermal efficiency with B20 and B40. Since thermal efficiency is the ratio of power to the fuel energy input, therefore, due to increased power and less fuel energy input with biodiesel blends, the thermal efficiency is more in case of the blends which matches the present study results (Fig. 6).
Figure 7 shows the effect of fuel type on the performance of Diesel cycle. By increasing the amount of work done by the fluid, the output efficiency also increases to a certain level and this process is similar for all three fuels. The only difference is that at a given thermal efficiency, much work is generated by biodiesel fuel. However, B20 is a reliable alternative fuel that gives engine performance at par with diesel fuel. Murrilo et al. (2007) observed similar behavior in case of the blends B10, B30 and B50, but slightly less efficiently in comparison to diesel which they attributed to fuel atomization during injection and its stability during storage, pumping and injection. Al-Dawody and Bhatti (2011) noticed that, among all tested fuels, B20 was the best tested fuel which gave the same performance results with good reduction in emissions as compared to pure diesel operation.

\section{Conclusion}

In this study, an air-standard Diesel cycle under irreversible heat transfer conditions was investigated. The effects of some engine parameters were presented using finite-time thermodynamic approach to evaluate fluid work output and cycle thermal efficiency. The intent of this study was to demonstrate trends towards a simple, easy and costless approach to evaluate the performance characteristics of Diesel engines fueled by biodiesel and its blends. So, an attempt has been made to provide reasonable values and results.

The fluid work and thermal efficiency of the Diesel cycle were predicted and analyzed by the model under varying compression ratio and cut-off ratio conditions for Diesel, biodiesel and B20. Depending upon the engine design parameters, the output work of the engine increases with compression ratio, the peak fluid work occurs at particular compression ratio, and any further increase in compression ratio results in decrease of output work. This is a characteristic of Diesel engine.

Also, the output work and thermal efficiency of the engine decreases with increase of cut-off ratio for all fuels which is a characteristic of Diesel engine. An increase in output work and efficiency was observed in case of biodiesel compared to diesel fuel but, B20 gives engine performance approximately at par with diesel fuel.

Numerical simulations showed that the performance of biodiesel and B20 fuels are similar to that of diesel fuel and especially B20 could be a good alternative fuel for conventional Diesel engines due to its low environmental pollutants and renewability. Therefore, it may not require modifications on Diesel engines to use biodiesel blends, especially B20. 
The comparison of the theoretical results and experimental data published in the open literature shows good agreement with each other. Results obtained from this study are a proper guide for designing and evaluating actual internal combustion engines and are also a good guide for designing engines that are basically designed for application of biodiesel and its blends as an operating fluid.

Acknowledgments The authors wish to express their thanks to Prof. Dr. Marzena Dzidafor his helpful comments and advice. The authors declare that they have no conflict of interest.

\section{References}

Agarwal AK, Das LM (2001) Bio-diesel development and characterization for use as a fuel in compression ignition engines. Trans ASME J Eng Gas Turb Power 123(2):440-447

Aksoy F (2011) The effect of opium poppy oil diesel fuel mixture on engine performance and emissions. Int $\mathrm{J}$ Environ Sci Tech $8(1): 57-62$

Al-Dawody MF, Bhatti SK (2011) Effect of soybean oil biofuel blending on the performance and emissions of Diesel engine using diesel-rk software. Int J Eng Sci Tech 3(6):4539-4555

Al-Hinti I, Akash B, Abu-Nada E, Al-Sarkhi A (2008) Performance analysis of air-standard Diesel cycle using an alternative irreversible heat transfer approach. Energy Convers Manage 49:3301-3304

Al-Sarkhi A, Jaber JO, Abu-Qudais M, Probert SD (2006) Effects of friction and temperature-dependent specific-heat of the working fluid on the performance of a Diesel-engine. Appl Energy 83:153-165

Angulo-Brown F, Fernandez-Betanzos J, Diaz-Pico CA (1994) Compression ratio of an optimized Ottocycle model. Eur J Phys 15(1):38-42

Atadashi IM, Aroua MK, Abdul Aziz A (2010) High quality biodiesel and its Diesel engine application: a review. Renew Sust Energ Rev 14(7):1999-2008

Aydin H, Bayindir H (2010) Performance and emission analysis of cottonseed oil methyl ester in a diesel engine. Renew Energy 35:588-592

Bejan A (1996) Entropy-generation minimization: the new thermodynamics of finite-size devices and finitetime processes. J Appl Phys 79(3):1191-1218

Canakci M (2007) Combustion characteristics of a turbocharged DI compression ignition engine fueled with petroleum diesel fuels and biodiesel. Bioresour Technol 98:1167-1175

Canakci M, Van Gerpen JH (2003) Comparison of engine performance and emissions for petroleum diesel fuel yellow grease biodiesel and soybean oil biodiesel. Trans ASAE 46(4):937-944

Chen L, Sun F (2004) Advances in finite-time thermodynamics: analysis and optimization. Nova Science Publishers, New York, pp 191-204

Chen L, Zen F, Sun F, Wu C (1996) Heat-transfer effects on the net work-output and power as a function of efficiency for an airstandard Diesel cycle. Energy 21(12):1201-1205

Chen L, Sun F, Wu C (1998) Optimal expansion of a heated workingfluid with linear phenomenological heat-transfer. Energy Convers Manage 39(3/4):149-156

Chen L, Wu C, Sun F (1999) Finite-time thermodynamic optimization or entropy-generation minimization of energy systems. J NonEquil Thermody 24(4):327-359
Chen L, Lin J, Luo J, Sun F, Wu C (2002) Friction effects on the characteristic performances of Diesel engines. Int J Energ Res 26(10):965-971

Chen L, Zheng T, Sun F, Wu C (2003) The power and efficiency characteristics for an irreversible Ottocycle. Int $\mathrm{J}$ Ambient Energy 24(4):195-200

Chen L, Sun F, Wu C (2004) The optimal performance of an irreversible Dual-cycle. Appl Energy 79(1):3-14

Dasilva FN, Prata SA, Teixeira JR (2003) Technical feasibility assessment of oleic sunflower methyl ester utilization in diesel bus engines. Energy Convers Manage 44:2857-2878

Dhar A, Kevin R, Agarwal AK (2012) Production of biodiesel from high-FFA neem oil and its performance emission and combustion characterization in a single cylinder DICI engine. Fuel Process Technol 97:118-129

Dzida M, Prusakiewicz P (2008) The effect of temperature and pressure on the physicochemical properties of petroleum diesel oil and biodiesel. Fuel 87:1941-1948

Environmental Protection Agency of USA (2002) A comprehensive analysis of biodiesel impacts on exhaust emissions. Draft technical report (EPA420-P-02-001) web. http://www.epa.gov/ oms/models/analysis/biodsl/p02001.pdf. Accessed October 2002

Ge Y, Chen L, Sun F, Wu C (2005) Reciprocating heat-engine cycle. Appl Energy 81:397-408

Ge Y, Chen L, Sun F (2006) Effect of heat transfer and friction on the performance of an irreversible air-standard Miller cycle. Int Commun Heat Mass 47:3224-3234

Ghatak A, Chakraborty S (2007) Effect of external irreversibilities and variable thermal properties of working fluid on thermal performance of a Dual internal combustion engine cycle. J Mech Eng 58:1-12

Gogoi TK, Baruah DC (2010) A cycle simulation model for predicting the performance of a Diesel engine fueled by diesel and biodiesel blends. Energy 35:1317-1323

Graboski MS, McCormick RL (1998) Combustion of fat and vegetable oil derived fuels in Diesel engines. Prog Energy Combust Sci 24:125-164

Heywood JB (1988) Internal combustion engine fundamentals. McGraw Hill, New York

Hoffman KH, Watowich SJ, Berry RS (1985) Optimal paths for thermodynamic systems: the ideal Diesel cycle. J Appl Phys 58(6):2125-2134

Hu Z, Tan P, Yan X, Lou D (2008) Life cycle energy environment and economic assessment of soybean-based biodiesel as an alternative automotive fuel in China. Energy 33:1654-1658

Klein SA (1991) An explanation for observed compression-ratios in internal-combustion engines. Trans ASME J Eng Gas Turb Power 113(4):511-513

Labeckas G, Slavinskas S (2006) The effect of rapeseed oil methyl ester on direct injection Diesel engine performance and exhaust emissions. Energy Convers Manage 47:1954-1967

Lapuerta M, Armas O, Rodriguez-Fernandez J (2008) Effect of biodiesel fuels on Diesel engine emissions. Prog Energy Combust Sci 34:198-223

Lin JC, Hou SS (2008) Effects of heat loss as percentage of fuel's energy friction and variable specific heats of working fluid on performance of air standard Otto cycle Energ. Convers Manage 49:1218-1227

Lin J, Chen L, Wu C, Sun F (1999) Finite-time thermodynamic performance of a Dual cycle. Int J Energy Res 23(9): $765-772$

Liu S, Wang Y, Oh JH, Herring JL (2011) Fast biodiesel production from beef tallow with radio frequency heating. Renew Energy 36:1003-1007

Ma F, Hanna MF (1999) Biodiesel production: a review. Bioresour Technol 70:1-15 
Moser BR, Williams A, Haas MJ, McCormick RL (2009) Exhaust emissions and fuel properties of partially hydrogenated soybean oil methyl esters blended with ultra low sulfur diesel fuel. Fuel Process Technol 90:1122-1128

Mozurkewich M, Berry RS (1982) Optimal paths for thermodynamic systems: the ideal Otto-cycle. J Appl Phys 53(1):34-42

Murrilo S, Miguez JL, Porteiro J, Granada E, Moran JC (2007) Performance and exhaust emissions in the use of biodiesel in outboard Diesel engines. Fuel 86:1765-1771

Oguz H, Saritas I, Baydan HE (2010) Prediction of Diesel engine performance using biofuels with artificial neural network. Expert Syst Appl 37:6579-6586

Oner C, Altun S (2009) Biodiesel production from inedible animal tallow and an experimental investigation of its use as alternative fuel in a direct injection Diesel engine. J Appl Phys 86(10): 2114-2120

Orlov VN, Berry RS (1993) Power and efficiency limits for internalcombustion engines via methods of finite-time thermodynamics. J Appl Phys 74(10):4317-4322

Qin X, Chen L, Sun F, Wu C (2003) The universal power and efficiency characteristics for irreversible reciprocating heatengine cycles. Eur J Phys 24(4):359-366

Raheman H, Phadatare AG (2004) Diesel engine emissions and performance from blends of karanja methyl ester and diesel. Biomass Bioenerg 27:393-397

Ramadhas AS, Jayaraj S, Muraleedharan C (2004) Use of vegetable oils as IC engine fuels: a review. Renew Energy 29:727-742

Ramadhas AS, Muraleedharan C, Jayaraj S (2005) Performance and emission evaluation of a Diesel engine fueled with methyl esters of rubber seed oil. Renew Energy 30:1789-1800

Rao GLN, Prasad BD, Sampath S, Rajagopald K (2007) Combustion analysis of Diesel engine fueled with jatropha oil methyl esterdiesel blend. Int J Green Energy 4:645-658
Rehman A, Sarviya RM, Pandey RK (2007) Investigation to ascertain the possibility of using non edible Karanja oil in CI engine with various oil modification. Proceedings of the 1st International Conference (2nd National Conference) on Advances in Energy Research, December 12-14, Institute of Technology, Bombay, India pp 419-425

Reyes JF, Sepulveda MA (2006) PM-10 emissions and power of a Diesel engine fueled with crude and refined biodiesel from Salmon oil. Fuel 85:1714-1719

Shehata MS, Abdel Razek SM (2011) Experimental investigation of Diesel engine performance and emission characteristics using jojoba/diesel blend and sunflower oil. Fuel 90:886-897

Srivathsan VR, Srinivasan LN, Karuppan M (2008) An overview of enzymatic production of biodiesel. Bioresour Technol 99(10): 3975-3981

Tsolakis A, Megaritis A, Wyszynski ML, Theinnoi K (2007) Engine performance and emissions of a Diesel engine operating on diesel-RME (rapeseed methyl ester) blends with EGR (exhaust gas recirculation). Energy 32:2072-2080

Usta N (2005) An experimental study on performance and exhaust emissions of a Diesel engine fueled with tobacco seed oil methyl ester. Energy Convers Manage 46:2373-2386

Wang W, Chen L, Sun F, Wu C (2002) The effects of friction on the performance of an air standard Dual cycle. Exergy 2(4):340-344

Zhang J, He K, Shi X, Zhao Y (2011) Comparison of particle emissions from an engine operating on biodiesel and petroleum diesel. Fuel 90(6):2089-2097

Zheng M, Mulenga MC, Reader GT, Tan Y, Wang M, Tjong J (2007) Neat biodiesel fuel engine tests and preliminary modeling. SAE Technical Paper. doi:10.4271/2007-01-0616

Zheng M, Mulenga MC, Reader GT, Wang M, Ting DSK, Tjong J (2008) Biodiesel engine performance and emissions in low temperature combustion. Fuel 87:714-722 